\title{
Management of dyspnea in palliative care
}

\author{
A.M. Crombeen MD CCFP(PC)* and E.J. Lilly MD CCFP*
}

\begin{abstract}
Dyspnea is a symptom commonly experienced by cancer patients that causes significant suffering, worsens throughout a patient's disease trajectory, and can be more difficult to manage than other symptoms. Assessment of dyspnea is best accomplished by a subjective description; physiologic measures are only weakly correlated with the patient's experience. It is important to consider a wide range of possible malignant and nonmalignant causes of dyspnea in cancer patients and to correct underlying causes where possible.

For patients with refractory dyspnea, opioids are a safe and effective treatment. Benzodiazepines can be considered, but the evidence for their use is weak. Supplemental oxygen is beneficial if patients are hypoxemic, or if they have concurrent chronic obstructive pulmonary disease. Nonpharmacologic strategies such as fan therapy, exercise programs, and pulmonary rehabilitation can also be beneficial. One important diagnosis to consider in all cancer patients is venous thromboembolism.

Prompt evaluation and treatment are vital to improving symptoms and outcomes for patients. Although dyspnea is common and potentially debilitating in cancer patients, it can be effectively managed with a structured approach to rule out reversible causes while concurrently treating the patient using appropriate therapeutic strategies.
\end{abstract}

Key Words Dyspnea, supplemental oxygen, opioids, venous thromboembolism

Curr Oncol. 2020 June:27(3)142-145

www.current-oncology.com

\section{INTRODUCTION}

At regional cancer centres, dyspnea is a symptom commonly experienced by cancer patients, at a prevalence close to $50 \%^{1}$. Dyspnea leads to considerable suffering for patients and caregivers, and can be a cause of treatment interruption, treatment discontinuation, emergency room attendance, and death ${ }^{2,3}$. Unlike other symptoms, dyspnea intensifies in severity throughout the duration of the patient's disease trajectory ${ }^{4,5}$. Assessing dyspnea can present the clinician with a diagnostic challenge when the selfreported distress of the patient is compared with physiologic measures obtained in a clinic visit or with findings from diagnostic imaging. Dyspnea also can be more difficult to treat than other symptoms (such as pain) commonly encountered by cancer patients ${ }^{5}$. This article addresses the diagnostic challenges that clinicians face when assessing dyspnea and discusses the pharmacologic and nonpharmacologic strategies that can be applied to address this burdensome symptom.

\section{MANAGING DYSPNEA}

\section{What Is the Best Way to Screen for Dyspnea in My Patient?}

Assessment of dyspnea is best achieved by obtaining a patient-reported description of the symptoms ${ }^{6,7}$. Dyspnea is defined by the American Thoracic Society as "a subjective experience of breathing discomfort that consists of qualitatively distinct sensations that vary in intensity."

Physiologic measures such as oxygen saturation, heart rate, and respiratory rate are only weakly associated with the patient's experience of dyspnea ${ }^{6}$. Compared with physiologic measures, caregiver assessment of the patient's dyspnea is more strongly associated with the patient's report of dyspnea. The subjective rating of dyspnea by the patient continues to be the standard on which the clinician should assess the symptom burden of dyspnea and monitor the benefits of any treatments provided. Validated patient-reporting scales such as the Edmonton Symptom Assessment System can be easily used by the patient or caregiver ${ }^{6}$. It is also important to screen for concurrent symptoms through a validated symptom scale such as the Edmonton Symptom Assessment System. The presence of depression, anxiety, tiredness, and lack of appetite is predictive of moderate-to-severe dyspnea in patients with cancer, and anxiety is associated with increased severity

This series is brought to you in partnership with the Canadian Association of General Practitioners in Oncology.

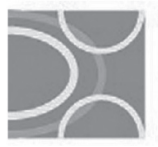
THE CANADIAN ASSOCIATION
OF GENERAL PRACTITIONERS
IN ONCOLOGY 
of dyspnea ${ }^{8}$. The interplay between dyspnea and other symptoms highlights the multidimensional nature of the suffering a patient with dyspnea experiences (Figure 1) ${ }^{9}$.

\section{What Are the Possible Causes of Dyspnea in My Patient?}

There are many potential causes of dyspnea, which can be categorized into malignant and nonmalignant causes. Table I presents a suggested approach to the potential causes of dyspnea in cancer patients. Frequently, multiple reasons for dyspnea exist simultaneously in the same patient. When evaluating a patient with dyspnea, it is crucial to consider a broad differential diagnosis and to apply a structured approach to investigation and treatment, while always keeping the patient's goals of care in mind.

\section{Consider Venous Thromboembolism in the Differential}

Venous thromboembolism (VTE), which includes both deep-vein thrombosis and pulmonary embolism, is a common complication of cancer and cancer treatment, with a reported prevalence of $4 \%-20 \%^{10}$. The 2 nd-leading cause of death in cancer patients ${ }^{11}$, VTE is associated with worse prognosis in a variety of malignancies ${ }^{12}$. Unfortunately, VTE can be difficult to recognize, leading to delayed diagnosis, prolongation of patient suffering, and potentially, death. Contrary to previously held beliefs, most fatal pulmonary emboli produce progressive breathlessness, fever, and tachycardia, taking an average of 2 hours to cause death ${ }^{13}$.

In oncology patients complaining of new or worsening dyspnea, it is important to consider VTE in the differential regardless of how long the individual has been living with cancer or receiving treatment. The risk of VTE is highest in the first 3-6 months after diagnosis, but remains significantly greater than that in the general population throughout the illness trajectory ${ }^{10,14}$. When evaluating a patient with cancer and with potential VTE, published data indicate that clinical prediction rules and D-dimer testing are insufficient to rule out VTE. All patients with suspected VTE should therefore be promptly imaged to rule out deepvein thrombosis, pulmonary embolism, or both ${ }^{15}$. Notably, up to $80 \%$ of pulmonary emboli will have no associated symptoms of deep-vein thrombosis ${ }^{14,16}$, and so absence of peripheral swelling or calf pain should not lower the index of suspicion for pulmonary embolism in a dyspneic patient.

If identified, vTE should be treated promptly with appropriate anticoagulant therapy. Details of vTE treatment are beyond the scope of this article, but many guidelines with further information are available. For complex thrombosis cases, consider referral to a nearby hematologist.

\section{What Pharmacologic Interventions Can Address Refractory Dyspnea in My Patient?}

The first step in managing dyspnea is identification and correction of any underlying cause or causes. However, many patients will have causes of dyspnea that cannot be corrected, or dyspnea will be refractory despite appropriate treatment of the underlying causes. For those patients, opioids are the mainstay of treatment regardless of the cause of the dyspnea. Multiple systematic reviews

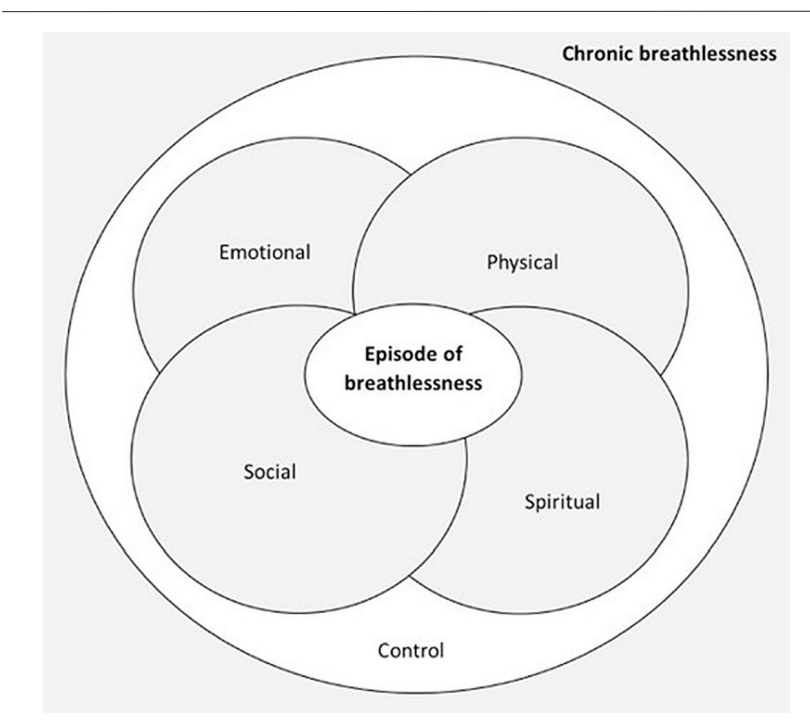

FIGURE 1 The experience of total breathlessness.

have demonstrated the effectiveness of various opioids (compared with placebo) for relief of dyspnea ${ }^{17-21}$. The effectiveness of opioids to relieve dyspnea is limited to oral and parenteral formulations; nebulized opioid therapy should not be used ${ }^{17}$. Effective relief can be achieved with doses as low as $10 \mathrm{mg}$ daily of oral morphine, and a ceiling effect is observed beyond $30 \mathrm{mg}$ daily of oral morphine ${ }^{2,22}$. At those doses, the typical adverse effects of opioids (sedation, nausea, constipation) might be observed, but they are self-limiting or manageable. Furthermore, such doses have not been shown to increase the risk of respiratory depression, hospital admission, or death ${ }^{17,18,22}$.

When prescribing opioids for dyspnea, we recommend starting with a regular dose of an immediate-release formulation (2.5-5 mg oral morphine or the equivalent, every 4-6 hours) to establish efficacy and tolerability. Once a stable dose has been achieved, consider switching to a slow-release formulation to assist with patient adherence and symptom control. Remember to also prescribe a stimulant laxative for constipation prophylaxis in all patients regularly receiving opioids.

The role of benzodiazepines to manage dyspnea remains less clear. The rationale for using a benzodiazepine would be to address the anxiety that is commonly reported as a component of dyspnea. A recent Cochrane review suggested that the evidence to recommend the routine use of benzodiazepines is insufficient ${ }^{23}$, although other studies suggest that benzodiazepines might be efficacious in addressing dyspnea ${ }^{17}$. Our practice has been to consider the use of a benzodiazepine in the presence of clear concomitant anxiety that is significantly contributing to the patient's experience of dyspnea, after an opioid has received a reasonable therapeutic trial.

\section{Will My Patient's Refractory Dyspnea Improve If I Prescribe Supplementary Oxygen?}

The use of supplementary oxygen can reduce the severity of dyspnea in patients who are hypoxemic (pulse oximetry $<88 \%$ on room air, or $\mathrm{PaO}_{2}<55 \mathrm{mmHg}$ ). Compared with 
TABLE I Potential causes of dyspnea in cancer patients

\begin{tabular}{|c|c|c|}
\hline Dyspnea type & Mechanism & Examples \\
\hline \multirow[t]{3}{*}{ Malignant } & $\begin{array}{l}\text { Direct tumour } \\
\text { effects }\end{array}$ & $\begin{array}{l}\text { - Bronchial compression } \\
\text { - Superior vena cava } \\
\text { obstruction } \\
\text { - Lymphangitic } \\
\text { carcinomatosis } \\
\text { - Venous thromboembolism }\end{array}$ \\
\hline & $\begin{array}{l}\text { Malignant } \\
\text { effusions }\end{array}$ & $\begin{array}{l}\text { - Pericardial effusion } \\
\text { - Pleural effusion } \\
\text { - Ascites }\end{array}$ \\
\hline & Treatment-related & $\begin{array}{l}\text { - Pneumonitis from systemic } \\
\text { therapy or radiation } \\
\text { - Lobectomy or } \\
\text { pneumonectomy }\end{array}$ \\
\hline \multirow[t]{3}{*}{ Nonmalignant } & Cardiovascular & $\begin{array}{l}\text { - Congestive heart failure } \\
\text { - Ischemic heart disease }\end{array}$ \\
\hline & Pulmonary & $\begin{array}{l}\text { - Chronic obstructive } \\
\text { pulmonary disease } \\
\text { - Interstitial lung disease } \\
\text { - Pneumonia } \\
\text { - Asthma }\end{array}$ \\
\hline & Other & $\begin{array}{l}\text { - Anemia } \\
\text { - Anxiety } \\
\text { - Obstructive sleep apnea } \\
\text { - Neuromuscular disease }\end{array}$ \\
\hline
\end{tabular}

using room air alone, provision of supplementary oxygen to patients who are dyspneic but not hypoxemic demonstrates little benefit in reducing symptom burden ${ }^{24}$. Despite that lack of evidence, supplementary oxygen is commonly requested by and prescribed to dyspneic patients ${ }^{17}$. It is important to distinguish whether a patient has chronic obstructive pulmonary disease and is hypoxemic, because providing supplementary oxygen in that patient population improves survival and functional status ${ }^{24}$.

Other nonpharmacologic interventions to provide relief to a dyspneic patient can be considered. Use of a handheld fan to create air movement across the face is thought to stimulate the trigeminal nerve, leading to shortterm (but not long-term) relief of dyspnea. The quality of the evidence for the use of handheld fans remains low ${ }^{25}$. Exercise programs and pulmonary rehabilitation programs for patients with comorbid chronic obstructive pulmonary disease might reduce dyspnea scores and improve quality of life when the predominant cause of dyspnea is the underlying chronic obstructive pulmonary disease ${ }^{17}$.

\section{SUMMARY}

The importance of screening for, evaluating, and treating dyspnea in patients with cancer cannot be understated. This common and debilitating symptom can be addressed with a structured approach to ruling out reversible causes of dyspnea while concurrently treating the patient with appropriately dosed opioid therapy.

\section{Key Points}

Dyspnea is a common symptom in patients with cancer. Patient-reported severity of dyspnea is the standard on which the clinician should base an evaluation of this symptom.

Opioid therapy is the first-line treatment for refractory dyspnea.

For new or suddenly worsening dyspnea in a patient with cancer, VTE should remain in the differential diagnosis.

The patient should be evaluated for concurrent symptoms that could make their dyspnea worse (anxiety, for instance).

\section{ACKNOWLEDGMENTS}

The authors acknowledge their peer reviewers, Drs. David Kim and Glen Maddison for feedback and guidance.

\section{CONFLICT OF INTEREST DISCLOSURES}

We have read and understood Current Oncology's policy on disclosing conflicts of interest, and we declare that we have none.

\section{AUTHOR AFFILIATIONS}

*Department of Family Medicine, Western University, London, ON.

\section{REFERENCES}

1. Dudgeon DJ, Kristjanson L, Sloan JA, Lertzman M, Clement K. Dyspnea in cancer patients: prevalence and associated factors. J Pain Symptom Manage 2001;21:95-102.

2. Abernethy AP, Currow DC, Frith P, Fazekas BS, McHugh A, Bui C. Randomised, double blind, placebo controlled crossover trial of sustained release morphine for the management of refractory dyspnoea. BMJ 2003;327:523-28.

3. Chin C, Booth S. Managing breathlessness: a palliative care approach. Postgrad Med J 2016;92:393-400.

4. Seow H, Barbera L, Sutradhar R, et al. Trajectory of performance status and symptom scores for patients with cancer during the last six months of life. JClin Oncol 2011;29:1151-8.

5. Guirimand F, Sahut d'izarn M, Laporte L, Francillard M, Richard JF, Aegerter P. Sequential occurrence of dyspnea at the end of life in palliative care according to the underlying cancer. Cancer Med 2015;4:532-9.

6. Hui D, Morgado M, Vidal M, et al. Dyspnea in hospitalized advanced cancer patients: subjective and physiologic correlates. J Palliat Med 2013;16:274-80.

7. Ontario Health (Cancer Care Ontario) [OH(CCO)]. Dyspnea (Shortness of Breath) [Web resource]. Toronto, ON: OH (CCO); 2010. [Available at: https://www.cancercareontario.ca/en/ symptom-management/3126; cited 3 January 2020]

8. McKenzie E, Zhang L, Chan S, et al. Symptom correlates of dyspnea in advanced cancer patients using the Edmonton Symptom Assessment System. Support Care Cancer 2020; 28:87-98.

9. Lovell N, Etkind SN, Bajwah S, Maddocks M, Higginson IJ. To what extent do the NRS and CRQ capture change in patients' experience of breathlessness in advanced disease? Findings from a mixed-methods double-blind randomized feasibility trial. J Pain Symptom Manage 2019;58:369-81.

10. Wang $\mathrm{H}, \mathrm{Xu} \mathrm{X}, \mathrm{Pu} \mathrm{C}, \mathrm{Li}$ L. Clinical characteristics and prognosis of cancer patients with venous thromboembolism. JCan Res Ther 2019;15:344-9.

11. Khorana AA, Francis CW, Culakova E, Kuderer NM, Lyman GH. Thromboembolism is a leading cause of death in cancer patients receiving outpatient chemotherapy. J Thromb Haemost 2007;5:632-4. 
12. Khorana AA. Venous thromboembolism and prognosis in cancer. Thromb Res 2010;125:490-3.

13. Havig O. Deep vein thrombosis and pulmonary embolism. An autopsy study with multiple regression analysis of possible risk factors. Acta Chir Scand Suppl 1977;478:1-120.

14. Noble S. Thromboembolic disease and breathlessness. Curr Opin Support Palliat Care 2016;10:249-55.

15. Peterson EA, Lee AYY. Update from the clinic: what's new in the diagnosis of cancer-associated thrombosis? Hematology Am Soc Hematol Educ Program 2019;2019:167-74.

16. Meignan M, Rosso J, Gauthier $\mathrm{H}$, et al. Systematic lung scans reveal a high frequency of silent pulmonary embolism in patients with proximal deep venous thrombosis. Arch Intern Med 2000;160:159-64.

17. Kamal AH, Maguire JM, Wheeler JL, Currow DC, Abernethy AP. Dyspnea review for the palliative care professional: treatment goals and therapeutic options. J Palliat Med 2012; 15:106-14.

18. Jennings AL, Davies AN, Higgins JPT, Gibbs JSR, Broadley KE. A systematic review of the use of opioids in the management of dyspnoea. Thorax 2002;57:939-44.

19. Ben-Aharon I, Gafter-Gvili A, Paul M, Leibovici L, Semmer SM. Interventions for alleviating cancer-related dyspnea: a systematic review. J Clin Oncol 2008;26:2396-404.
20. Viola R, Kiteley C, Lloyd NS, Mackay JA, Wilson J, Wong RKS on behalf of Supportive Care Guidelines Group of the Cancer Care Ontario Program in Evidence-Based Care. The management of dyspnea in cancer patients: a systematic review. Support Care Cancer 2008;16:329-37.

21. Allard P, Lamontagne C, Bernard P, Tremblay C. How effective are supplementary doses of opioids for dyspnea in terminally ill cancer patients? A randomized continuous sequential clinical trial. J Pain Symptom Manage 1999;17:256-65.

22. Currow DC, McDonald C, Oaten S, et al. Once-daily opioids for chronic dyspnea: a dose increment and pharmacovigilance study. J Pain Symptom Manage 2011;42:388-99.

23. Simon ST, Higginson IJ, Booth S, Harding R, Weingartner V, Bausewein C. Benzodiazepines for the relief of breathlessness in advanced malignant and non-malignant diseases in adults. Cochrane Database Syst Rev 2016;10:CD007354.

24. Abernethy AP, McDonald CF, Firth PA, et al. Effect of palliative oxygen versus room air in relief of breathlessness in patients with refractory dyspnoea: a double-blind, randomized controlled trial. Lancet 2010;376:784-93.

25. Yu S, Sun K, Xing X, et al. Fan therapy for the relief of dyspnea in adults with advanced disease and terminal illness: a meta-analysis of randomized controlled trials. J Palliat Med 2019;22:1603-9. 